Faculty and staff at Indiana University-Purdue University Indianapolis (IUPUI) have developed several tools to assess campus civic engagement initiatives. This chapter describes the IUPUI Faculty Survey and the Civic-Minded Graduate Scale, and reports on findings from campus-based assessment and research.

\title{
Assessing Civic Engagement at Indiana University-Purdue University Indianapolis
}

\author{
Gary R. Pike, Robert G. Bringle, Julie A. Hatcher
}

As a result of the renewed interest in community service, service learning, and civic engagement during the 1990s, America's colleges and universities are developing new models for how they relate to their communities. The foundation and inspiration for developing approaches to civic engagement were put forth by Ernest Boyer who wrote extensively on the role of service, community, and values in education. Boyer (1996) promoted a new model for higher education in which "the academy must become a more vigorous partner in searching for answers to our most pressing social, civic, economic, and moral problems, and it must affirm its historic commitment to society" (pp. 19-20). He noted that, "What is needed is not just more programs, but a larger purpose, a larger sense of mission, a larger clarity of direction" (Boyer, 1994, p. A48).

The emergence of civic engagement has been evident in all types of institutions, including community colleges, liberal arts institutions, comprehensive universities, metropolitan universities, professional schools, and large research universities. Institutions of higher education have begun to reexamine the structures, frameworks, and procedures associated with civic engagement activities, including the nature of the scholarship of engagement (Brukardt, Holland, Percy, \& Zimpher, 2004; O'Meara \& Rice, 2005). In a study by O'Meara (2005), two out of three of the 729 chief academic officers surveyed reported that, during the previous 10 years, their institutions had changed mission and planning documents, amended faculty evaluation criteria, provided incentive grants, or developed flexible workload programs as a basis for a broader definition of scholarly work. Nevertheless, only about one third of the chief academic officers observed increases in the scholarship of integration, student contact with faculty, and scholarship 
focused on civic engagement and professional service. Based on these results much more needs to be done to fulfill the promise of civic engagement. An important element in this process is assessing the alignment between institutions' civic engagement goals and the ways in which civic engagement is supported and implemented on and off campus.

\section{Service Learning and Civic Engagement}

Although there are many forms of civic engagement, service learning courses represent one of the best approaches for reaching the most central goals of engaging students in ways that contribute to their civic knowledge, skills, and habits (Battistoni, 2001; Eyler \& Giles, 1999). We limit service learning to curricular civic engagement by defining it as a "course-based, credit-bearing educational experience in which students (a) participate in an organized service activity that meets identified community needs and (b) reflect on the service activity in such a way as to gain further understanding of course content, a broader appreciation of the discipline, and an enhanced sense of personal values and civic responsibility" (Bringle $\&$ Hatcher, 1995, p. 112). In contrast to many other examples of applied learning and community-based instruction (e.g., cooperative education, field studies, internships, practicum), service learning has as an intentional educational goal the students' civic education and growth. From the point of view of the academy, service learning involves faculty, students, and professional staff in educationally meaningful community service through the curriculum. Service learning also embodies qualities and values to which current models of civic engagement aspire: meeting community and academic goals through reciprocal, democratic partnerships in ways that incorporate all constituencies as coeducators, colearners, and cogenerators of knowledge and that promote the growth and respect of all constituencies (Saltmarsh \& Hartley, 2011).

Service learning is one of the fundamental indicators for Carnegie's voluntary classification for Community Engagement, further evidence of the centrality of service learning in developing new models for civic engagement in higher education (Driscoll, 2008). The values, processes, collaborations, and goals of service learning courses provide models for other forms of civic engagement focused on research (e.g., participatory action research) and professional service (e.g., collaborative partnerships with the community) (Bringle, Hatcher, \& McIntosh, 2006). The prevalence of service learning courses has increased dramatically in the past two decades across the spectrum of disciplines and professional programs (Campus Compact, 2012). An average of 66 service learning courses per campus was reported by Campus Compact's Annual Membership Survey in 2012 compared to an average of 35 courses reported in 2006, and this represented $7 \%$ of the faculty involved in teaching service learning courses (Campus Compact, 2012). 


\section{Assessing Service Learning}

Bringle and Hatcher (2009) examined dossiers from the first cohort of campuses successfully applying for the elective Carnegie Community Engagement Classification and concluded that the evidence presented to assess service learning courses mirrored general practice in higher education. Assessment in this first cohort was heavily dependent on self-report instruments. Some aggregation of data across the curriculum was reported, but it was quite limited and had little coordination to other forms of institutional research and evaluation. The College Student Report, developed as part of the National Survey of Student Engagement (NSSE), which permits comparisons with peer institutions, was one example that was cited in documentation. Another example was the College Senior Survey (CSS) developed by the Higher Education Research Institute (HERI). Both questionnaires are limited in that they only capture students' self-reports of the level of their involvement in a limited range of civic activities.

A survey developed by the American Association of State Colleges and Universities (AASCU) provides students with an opportunity to respond to a wider array of questions about service learning and civic engagement (Ouimet \& Pike, 2008). However, these surveys are limited in the information they provide about what works to promote service learning and civic engagement. Moreover, these surveys are not designed to explore the impact of these activities on student learning outcomes or community outcomes. In the sections that follow we describe the development of two surveys designed to (a) assess faculty attitudes and behaviors that influence the prevalence of service learning and civic engagement in higher education and (b) identify the effects of service learning on student civic outcomes.

\section{National Assessment of Faculty Attitudes and Behaviors}

Faculty members' attitudes toward service learning and civic engagement and the extent to which faculty members are involved in their communities are important factors in the success of civic engagement and service learning (Bringle, Jones, \& Pike, 2009). Accordingly, the creators of the NSSE College Student Report and the HERI CSS have developed faculty surveys of their involvement in service learning and civic activities. For example, the Faculty Survey of Student Engagement (FSSE) asks faculty members whether they believe it is important that students participate in community service or volunteer work, whether they themselves participate in community service activities, and whether they include service learning activities in their courses (Center for Postsecondary Research, 2009). The HERI Faculty Survey asks participants if they teach service learning courses, participate in community service, and think instilling in students a commitment to community service is an important learning outcome of an undergraduate education (Higher Education Research Institute, 2007). The HERI survey also 
asks faculty members whether civic engagement and service learning are priorities at their institutions, and whether colleges and universities should be engaged in community service.

Both FSSE and the HERI Faculty Survey provide useful baseline data about faculty members' use of and support for service learning. The surveys also provide data against which institutional results can be compared to other institutions. However, both surveys measure faculty attitudes and behaviors at a very general level. Neither provides much information about why faculty members do or do not support service learning.

\section{The IUPUI Faculty Survey}

In preparation for its 2002 reaccreditation by the Higher Learning Commission, Indiana University-Purdue University Indianapolis (IUPUI) revised its mission to emphasize (a) teaching and learning; (b) research, scholarship, and creative activity; and (c) civic engagement locally, nationally, and globally. The institution also developed a series of three or four performance objectives for each area of emphasis. At the same time, the IUPUI Faculty Survey was revised to elicit information about faculty members' attitudes and behaviors regarding service learning and civic engagement. The survey data are used to evaluate progress toward the institution's civic engagement goals. The data were also used to provide evidence to support the inclusion of IUPUI in the elective Carnegie Classification for Community Engagement.

For the spring 2005 administration of the IUPUI Faculty Survey, 19 items were added to assess faculty members' attitudes and behaviors related to service learning and civic engagement. Nine of the survey questions measured intrinsic and extrinsic factors related to faculty attitudes toward service learning and civic engagement. Previous research has identified a variety of intrinsic and extrinsic factors that are related to faculty attitudes toward service learning. Intrinsic factors include gender, race/ethnicity, personal values, and academic discipline (Abes, Jackson, \& Jones, 2002; Antonio, Astin, \& Cress, 2000), whereas extrinsic factors include institutional mission and type, faculty reward structures, and institutional support for community service (Antonio et al., 2000; O'Meara, 2002, 2005). Faculty were asked whether they strongly agreed, agreed, were neutral, disagreed, or strongly disagreed with statements such as "the university should facilitate student involvement in community service as part of the undergraduate learning experience" (intrinsic factor) and "devoting professional or academic expertise to the community is valued highly in my department or program" (extrinsic factor).

The survey also asked faculty members about the extent of their involvement in a wide variety of civic activities. The types of involvement ranged from teaching a service learning course, to publishing an article dealing with service learning or civic engagement, to being actively involved in 


\section{Table 8.1. Principal Component Loadings for Items About Faculty Attitudes}

\begin{tabular}{|c|c|c|c|}
\hline Items & $I$ & II & III \\
\hline $\begin{array}{l}\text { Faculty in my discipline have a professional obligation } \\
\text { to apply their knowledge to problems in society }\end{array}$ & 0.62 & & \\
\hline $\begin{array}{l}\text { The university should facilitate student involvement } \\
\text { in community service as part of the undergraduate } \\
\text { learning experience }\end{array}$ & 0.79 & & \\
\hline $\begin{array}{l}\text { Preparing students for responsible citizenship should } \\
\text { be an integral part of the undergraduate experience }\end{array}$ & 0.74 & & \\
\hline $\begin{array}{l}\text { IUPUI has a responsibility to contribute to the } \\
\text { economic development of our community }\end{array}$ & 0.71 & & \\
\hline $\begin{array}{l}\text { Devoting professional or academic expertise to the } \\
\text { community is valued highly in my department or } \\
\text { program }\end{array}$ & & 0.73 & \\
\hline $\begin{array}{l}\text { There is a high level of commitment on this campus to } \\
\text { civic engagement as an integral part of IUPUI } \\
\text { culture }\end{array}$ & & 0.79 & \\
\hline $\begin{array}{l}\text { There is a high level of commitment in my department } \\
\text { or program to promoting the civic engagement of } \\
\text { faculty }\end{array}$ & & 0.88 & \\
\hline $\begin{array}{l}\text { The goal of a scholar is to advance knowledge without } \\
\text { regard to the possible implications for society }\end{array}$ & & & 0.88 \\
\hline $\begin{array}{l}\text { Attention to civic engagement detracts from the more } \\
\text { important work of teaching and scholarship }\end{array}$ & & & 0.69 \\
\hline
\end{tabular}

a campaign for public office. The response options for these activity questions were never, once or twice, occasionally, and frequently.

During the spring 2005 semester, the survey was administered via the web to 1,889 full-time faculty members who were affiliated with academic programs on the IUPUI campus. Slightly different versions of the survey were developed for medical school and non-medical school faculty; however, the 19 civic engagement items were the same for both versions of the survey (see Indiana University-Purdue University Indianapolis, 2005). After multiple follow-up email reminders, responses were received from 1,001 faculty members representing a 53\% response rate.

A principal components analysis of faculty members' responses to the nine items about attitudes toward service learning and civic engagement produced a three-component solution. The items and loadings for the varimax-rotated components are presented in Table 8.1. To facilitate interpretation only loadings of 0.40 or greater are shown. The first component contained four items. The items all dealt with faculty members' attitudes about service learning and civic engagement and represent an intrinsic orientation. Three items had substantial loadings on the second component and represent an extrinsic orientation because they focused on perceived institutional support for service learning and civic engagement. 
Table 8.2. Principal Component Loadings for Items About Faculty Activities

\begin{tabular}{lcc}
\hline Items & $I$ & II \\
\hline $\begin{array}{l}\text { Taught a class that included a significant component of } \\
\text { service (e.g., a service learning class) }\end{array}$ & 0.68 \\
Engaged in a research project with a community partner & 0.68 \\
Participated in a professional capacity on a board or & \\
$\quad$ committee of a business, nonprofit, or government & 0.66 \\
$\quad$ agency & 0.69 \\
Gave a talk or presentation to a community organization & 0.66 \\
$\begin{array}{l}\text { Included in my classes materials or activities that } \\
\text { promote civic engagement among students }\end{array}$ & 0.72 \\
$\begin{array}{l}\text { Provided professional services to a community group, } \\
\quad \text { business, or government organization }\end{array}$ & \\
Participated in a campus- or school-sponsored & \\
$\quad$ community service event (e.g., United Way Day of & \\
$\quad$ Caring, Race for the Cure, Martin Luther King, Jr., & 0.45 \\
$\quad$ Day of Service, etc.) & 0.50 \\
Published an article that addressed civic engagement & \\
Participated actively in a campaign for public office & \\
Advocated for a cause or public issue in the community & \\
\hline
\end{tabular}

The final component included two items. Interestingly, these two questions were worded to measure negative attitudes toward civic engagement. Follow-up analyses also revealed that the first two factors could be used to construct dependable scales. Measures of internal consistency were 0.73 and 0.79 , respectively, for the first two factors. The two negatively worded items did not produce a dependable measure.

A principal components analysis of the 10 activity items identified two interpretable components. The 10 items in the analysis, along with their varimax-rotated loadings, are presented in Table 8.2. Eight items were associated with a general community-involvement dimension and could be used to construct a reliable scale of faculty members' involvement in the community $(\alpha=0.81)$. The remaining two questions focused on faculty members' involvement in political activities and did not provide a dependable measure that could be used as a second activities scale.

These scales have been very useful in assessing the status of faculty attitudes, tracking trends across time, profiling civic engagement at IUPUI, and identifying opportunities for improving civic engagement, particularly at the academic unit level (i.e., college or school). For example, faculty members at IUPUI generally hold positive attitudes toward service learning and civic engagement, but some units (such as the School of Social Work) are substantially more favorable in their attitudes than others (such as the School of Science). Results for individual questions have also been useful assessment tools. Faculty members in the School of Social Work reported the highest levels of involvement in civic activities and also perceived 
campus support for civic engagement to be strong (4.45 on a 5-point scale). In contrast, faculty members in the School of Medicine reported relatively low levels of involvement and tended, on average, to disagree with the view that the campus supported civic engagement (2.89 on a 5-point scale where a score of 3 represented a neutral response). These results have led some schools to reevaluate their support for civic engagement and service learning.

\section{The IUPUI Civic-Minded Graduate Scale}

The Center for Service and Learning (CSL) is a centralized unit on IUPUI's campus with a mission to involve students, faculty, and staff in service activities that mutually benefit the campus and community (see http://csl.iupui .edu/). CSL staff work with faculty on the design and implementation of service learning courses, conduct assessment and research on service learning courses, coordinate volunteer community service opportunities, manage community-based Federal Work-Study programs (e.g., America Reads, America Counts), focus civic engagement activities in a particular set of neighborhoods in Indianapolis through strategic partnerships, and involve more than 200 students each year in the Sam H. Jones Community Service Scholarship program. Across all programs, CSL staff work to create educationally meaningful service opportunities for IUPUI undergraduate and graduate students.

Based upon an extensive literature review (e.g., Daloz, Keen, Keen, \& Parks, 1996; Hatcher, 2008; Moely, Mercer, Ilustre, Miron, \& McFarland, 2002; Sullivan, 1995, 2005), and a review of scales and measurement procedures used by other campuses (e.g., Tufts University, Tulane University, University of Maryland College Park), a set of characteristics were identified for the knowledge, skills, dispositions, and behavioral intentions that are characteristic of a civic-minded student and, therefore, graduate. Next we compiled a list of student learning outcomes for each of the subcomponents. This list was vetted with two focus groups comprised of informed scholars and program staff with service learning and cocurricular service programs on campus. This produced a consensus of key student learning outcomes that could be applied across service learning courses, curricula (e.g., programs, majors), and cocurricular service programs.

Based on this work, the civic-minded graduate is defined as "someone who has completed a course of study (e.g., bachelor's degree) and has the capacity and desire to work with others to achieve the common good" (Bringle \& Steinberg, 2010, p. 429). "Civic-mindedness" refers to a person's inclination or disposition to be knowledgeable of and involved in the community, and to have a commitment to act upon a sense of responsibility as a member of that community. Thus, the concept refers to a person's orientation toward the community and other people in the community, as distinct from orientations towards self, family, or corporate/profit 
concerns. An additional way of considering the nature of the civic-minded student and graduate is that it is the intersection of (a) identity, (b) educational experiences, and (c) civic experiences. The learning outcomes were then operationalized into 30 items for the Civic-Minded Graduate (CMG) scale (see http://csl.iupui.edu/teaching-research/opportunities/ civic-learning/graduate.shtml). The CMG Scale was developed to evaluate students' civic engagement outcomes at the course level, the academic unit level, the program level (e.g., service-based scholarship program), and the institutional level.

After a pilot study, the CMG Scale was administered to 86 students who were scholarship recipients or Federal Work-Study tutors in CSL programs at IUPUI. Students were asked to respond to each item by selecting strongly agree, agree, neutral, disagree, or strongly disagree. The CMG Scale showed high reliability/internal consistency $(\alpha=0.96)$. Results of the factor analysis were tentative due to small sample size, but the best solution pointed to one factor that accounted for $45.7 \%$ of the variance in responses. This provides supportive evidence that the scale measures one construct, civicmindedness. In order to evaluate discriminant validity the Marlowe-Crowne Social Desirability Scale, Form C (Reynolds, 1982) was also administered. Responses on the CMG Scale had a low $(r=.13)$, nonsignificant correlation with Marlowe-Crowne responses. This offers additional support for the construct validity of the CMG Scale, indicating that, although civicmindedness is a positive trait, the instrument is not simply a measure of social desirability.

In addition, the Integrity Scale for community service, which is designed to assess Morton's (1995) concept of depth of integration between community service values and action (Bringle et al., 2006), was also included. Because the CMG Scale and Integrity Scale measure related concepts, a positive correlation between the two scales was expected. Data analysis indicated a significant correlation between responses on the CMG and Integrity Scales $(r=.32, p<.01)$, which demonstrates the convergent validity of the CMG Scale, and offers further support for the construct validity of the instrument.

A follow-up study was conducted of a random sample of undergraduate students across all majors at IUPUI $(n=606,13.8 \%$ response rate) to evaluate the validity of the CMG Scale by triangulating across multiple measures and methods including the CMG Narrative (a written qualitative measure) and the CMG Interview (an oral qualitative measure). These two measures, and corresponding rubrics, were designed to (a) gather and evaluate qualitative evidence on the construct of civic-mindedness, and (b) evaluate the convergent validity evidence of the CMG Scale.

The participant sample completed an online survey that included items on prior experience (e.g., enrollment in service learning courses, volunteering), the CMG Scale, and the CMG Narrative. The CMG Narrative asks students to write a reflective response to the following prompt: I have a 
responsibility and a commitment to use the knowledge and skills I have gained as a college student to collaborate with others, who may be different from me, to help address issues in society. A total of 397 respondents completed both the CMP Scale and this narrative prompt on the survey. A second e-mail was sent to 200 students randomly selected from the participant sample, inviting their participation in face-to-face interviews. A total of 41 students participated in interviews using the CMG Interview protocol, of which 29 had also completed both the CMG Scale and CMG Narrative.

Results from this campus study showed high reliability/internal consistency of the CMG Scale $(\alpha=0.96)$, and principal component factor analysis indicated one factor that accounted for $49.4 \%$ of the variance in responses. These results lend further support for its construct validity. Consistent with earlier studies, the number of service learning classes a student had taken was positively correlated with the CMG Scale, $r(595)=.34, p<.001$, providing further evidence for construct validity. Two rubrics were designed and a team of three was trained to use the rubrics to evaluate qualitative evidence from both the CMG Interview and the CMG Narratives. There were no statistically significant differences in ratings of narrative responses between the Interviewed Group and Group Not Interviewed, $F(1,68)=.21$, $p>.05$, indicating that the interviewees' narratives were not significantly different from the larger sample. The total scores of the CMG Interview had a significant correlation with CMG Scale, $r(39)=.49, p<.01$. In addition, evidence from the CMG Narrative had a significant correlation with the CMG Scale, $r(27)=.45, p<.01$. Taken together, these results support the construct validity of the CMG Scale, indicating that the CMG Narrative and Interview protocol are useful measures of the CMG construct (Steinberg, Hatcher, \& Bringle, 2011).

The importance of this research lies in the future use of the CivicMinded Graduate Scale, Narrative, and Interview protocol for educators and practitioners who design programs to support the civic and voluntary participation of college graduates. This research will increase the capacity for empirical research, using self-report and authentic evidence, on the civic dimensions of graduates and preprofessionals by measuring civic-mindedness as either an independent or dependent variable. This research will permit greater understanding of the extent to which educational strategies (e.g., service learning courses, international service learning courses, pro bono programs in professional schools) cultivate civic-mindedness among college graduates.

\section{Conclusion}

Institutional assessment plays an important role in improving practice in higher education. Gathering systematic data provides insight into campus culture and student learning, and it can help guide the allocation of resources. As more campuses devote resources to support service learning 
and civic engagement, it is imperative that assessment strategies provide information on trends among faculty and students.

\section{References}

Abes, E. S., Jackson, G., \& Jones, S. R. (2002). Factors that motivate and deter faculty use of service-learning. Michigan Journal of Community Service Learning, 9(1), 5-17.

Antonio, A. L., Astin, H. S., \& Cress, C. M. (2000). Community service in higher education: A look at the nation's faculty. The Review of Higher Education, 23(4), 373-398.

Battistoni, R. (2001). Civic engagement across the curriculum: A resource book for servicelearning faculty in all disciplines. Providence, RI: Campus Compact.

Boyer, E. L. (1994, March 9). Creating the new American college. Chronicle of Higher Education, A48.

Boyer, E. L. (1996). The scholarship of engagement. Journal of Public Service and Outreach, 1(1), 11-20.

Bringle, R. G., \& Hatcher, J. A. (1995). A service-learning curriculum for faculty. Michigan Journal of Community Service Learning, 2, 112-122.

Bringle, R. G., \& Hatcher, J. A. (2009). Innovative practices in service learning and curricular engagement. In L. Sandmann, A. Jaeger, \& C. Thornton (Eds.), New directions in community engagement (pp. 37-46). San Francisco, CA: Jossey-Bass.

Bringle, R. G., Hatcher, J. A., \& McIntosh, R. (2006). Analyzing Morton's typology of service paradigms and integrity. Michigan Journal of Community Service Learning, 13(1), 5-15.

Bringle, R. G., Jones, S. G., \& Pike, G. R. (2009). Faculty perceptions of civic engagement and service learning. In M. Moore \& P. L. Lind (Eds.), Service-learning in higher education: Paradigms and challenges (pp. 17-27). Indianapolis: University of Indianapolis Press.

Bringle, R. G., \& Steinberg, K. S. (2010). Educating for informed community involvement. American Journal of Community Psychology, 46, 428-441.

Brukardt, M. J., Holland, B., Percy, S. L., \& Zimpher, N. (2004). Calling the question: Is higher education ready to commit to community engagement? A Wingspread statement. Milwaukee: Milwaukee Idea Office, University of Wisconsin-Milwaukee.

Campus Compact. (2012). Creating a culture of assessment. Annual Membership Survey. Providence, RI: Campus Compact. Retrieved from http://www.compact .org/wp-content/uploads/2013/04/Campus-Compact-2012-Statistics.pdf

Center for Postsecondary Research. (2009). About FSSE. Bloomington, IN: Author. Retrieved from http://fsse.iub.edu/html/about.cfm\#anchor_0

Daloz, L. A., Keen, C. H., Keen, J. P., \& Parks, S. D. (1996). Common fire: Lives of commitment in a complex world. Boston, MA: Beacon Press.

Driscoll, A. (2008). Carnegie's Community-Engagement Classification: Intentions and insights. Change, January/February, 38-41.

Eyler, J., \& Giles, D. E., Jr. (1999). Where's the learning in service-learning? San Francisco, CA: Jossey-Bass.

Hatcher, J. A. (2008). The public role of professionals: Developing and evaluating the CivicMinded Professional scale (Doctoral dissertation). Available from ProQuest Dissertations and Theses database. (AAT 3331248)

Higher Education Research Institute. (2007). The HERI Faculty Survey. Los Angeles, CA: Author. Retrieved from http://www.heri.ucla.edu/facoverview.php

Indiana University-Purdue University Indianapolis. (2005). Civic Engagement Survey. Retrieved from http://www.imir.iupui.edu/newsite/Surveys/Reports/details/faculty/ 2005/pdf/surveyInstrumentnonMed.pdf and http://www.imir.iupui.edu/newsite/ Surveys/Reports/details/faculty/2005/pdf/surveyInstrumentMed.pdf 
Moely, B. E., Mercer, S. H., Ilustre, V., Miron, D., \& McFarland, M. (2002). Psychometric properties and correlates of the Civic Attitudes and Skills Questionnaire (CASQ): A measure of students' attitudes related to service-learning. Michigan Journal of Community Service Learning, 8(2), 15-26.

Morton, K. (1995). The irony of service: Charity, project, and social change in servicelearning. Michigan Journal of Community Service Learning, 2, 19-32.

O'Meara, K. A. (2002). Uncovering the values in faculty evaluation of service as scholarship. The Review of Higher Education, 26(1), 57-80.

O'Meara, K. A. (2005). Effects of encouraging multiple forms of scholarship nationwide and across institutional types. In K. O'Meara \& R. E. Rice (Eds.), Faculty priorities reconsidered: Rewarding multiple forms of scholarship (pp. 255-289). San Francisco, CA: Jossey-Bass.

O'Meara, K. A., \& Rice, R. E. (Eds.). (2005). Faculty priorities reconsidered: Rewarding multiple forms of scholarship. San Francisco, CA: Jossey-Bass.

Ouimet, J. A., \& Pike, G. R. (2008). Rising to the challenge: Developing a survey of workplace skills, civic engagement, and global awareness. In V. Borden \& G. Pike (Eds.), New Directions for Institutional Research Series: Assessment Supplement 2007. Assessing and accounting for student learning: Beyond the Spellings Commission (pp. 71-82). San Francisco, CA: Jossey-Bass.

Reynolds, W. M. (1982). Development of reliable and valid short form of the MarloweCrowne Social Desirability scale. Journal of Clinical Psychology, 38(1), 119-125.

Saltmarsh, J., \& Hartley, J. M. (Eds.). (2011). To serve a larger purpose: Engagement for democracy and the transformation of higher education. Philadelphia, PA: Temple University Press.

Steinberg, K., Hatcher, J. A., \& Bringle, R. G. (2011). The civic-minded graduate: A north-star. Michigan Journal of Community Service Learning, 18, 19-33.

Sullivan, W. M. (1995). Work and integrity: The crisis and promise of professionalism in America. New York, NY: HarperCollins.

Sullivan, W. M. (2005). Work and integrity: The crisis and promise of professionalism in America (2nd ed.). San Francisco, CA: Jossey-Bass.

GARY R. PIKE is a professor of higher education and student affairs at the Indiana University School of Education-IUPUI.

RoBert G. BRINGLE is Chancellor's Professor Emeritus of psychology and philanthropic studies, and a senior scholar at the Center for Service and Learning at Indiana University-Purdue University Indianapolis.

Julie A. HATCHER is an associate professor of philanthropic studies and currently serves as executive director of Center for Service and Learning at Indiana University-Purdue University Indianapolis. 
Copyright of New Directions for Institutional Research is the property of John Wiley \& Sons, Inc. and its content may not be copied or emailed to multiple sites or posted to a listserv without the copyright holder's express written permission. However, users may print, download, or email articles for individual use. 